\title{
Complementary Effect of Exercise in Cardiovascular Medicine
}

\section{Yeung PK $^{1^{*}}$ and Jodi Tinkel ${ }^{2}$}

${ }^{1}$ Department of Medicine, College of Pharmacy, Dalhousie University, Halifax, NS, Canada

${ }^{2}$ University of Toledo Medical Center, Toledo, $\mathrm{OH} 43614$, USA

Cardiovascular disease, including stroke, is the leading cause of death and disability worldwide, and is an enormous economic burden to our societies [1]. Based on the latest statistics released for heart and stroke disease, an estimated 83,600,000 adults in the United State (US) (>30\%) have one form or another of cardiovascular disease (CVD), including more than $90 \%$ with hypertension, $18 \%$ with coronary heart disease (CHD), close to $10 \%$ with myocardial infarction (MI) and $8 \%$ with stroke. The total direct and indirect cost in the US alone for treatment of CVD (hospitalization, drugs, home healthcare, etc.), and lots of productivity and morbidity is estimated at close to $\$ 315$ billion US per year [2]. Thus, prevention and early treatment of the major CV risk factors could provide huge savings in health care costs worldwide. Despite major advances in treatment of cardiovascular disease, the prevalence of hypertension, ischemic heart disease (IHD) and stroke is still on the rise. Identifying optimal strategies in preventing the development of $\mathrm{CV}$ risk factors and slow disease progression remains a therapeutic challenge.

Exercise is increasingly recommended in both primary and secondary prevention strategies to enhance health, reduce risk factors and optimize therapeutic management of cardiovascular diseases [3-9]. Lack of physical activity is recognized as one of four major behavioural, and therefore, modifiable risk factors in the development of CVD [10]. It is believed that regular exercise is one of the most important non-pharmacological tools in reducing overall cardio metabolic risk. Aerobic exercise significantly reduces body weight, blood pressure (BP), blood glucose and lipid levels, and also improves strength, flexibility and quality of life [4]. A single bout of swimming exercise has been shown to sustain left ventricular function after isoproterenolinduced injury in mice, which lasted over 4 weeks after the exercise [11]. Similarly, treadmill exercise has also been shown to have prolonged cardiovascular protective effects against injury induced by isoproterenol in rat $[12,13]$. In patients with stable systolic heart failure, exercise training can relieve symptoms, improve functional capacity and quality of life, as well as reduce hospitalizations and all cause mortality $[14,15]$. Conversely, lack of exercise or physical inactivity is a significant cardiovascular risk factor [5]. There is also evidence to suggest that exercise intensity, as well as duration and frequency, is an important variable in determining cardiovascular protection $[16,17]$. However, applying this evidence into practice must take into account individual differences in baseline fitness, compliance and the independent risk associated with a sedentary lifestyle [18].

The mechanism of cardiovascular protection induced by exercise is not fully elucidated or quantified. It is certainly multi-factorial and includes improvements in cardiovascular risk factors, enhanced fibrinolysis, improved endothelial function, decreased sympathetic tone and other as-yet-undetermined factors [5]. It is known that exercise also activates the neuroendocrine system [19], and triggers release of myokines from skeletal muscle, mediating cross-talk within the cardiovascular system. Some biomarkers such as interleukin-6 (IL-6) can serve as energy sensors and may play an important role in cardiovascular protection [20-22]. Exercise is a form of ischemic preconditioning, and individuals who exercise regularly and experience a clinical ischemic event, such as an MI, have a smaller infarct size and overall improved left ventricular systolic function [23]. Mechanistically, the beneficial effects of exercise pre-conditioning on endothelial function and the myocardium may be mediated via increased blood flow, enhanced nitric oxide production and bioavailability, changes in neurohormonal release, improvements in oxidant/antioxidant balance and optimization of energy and ATP metabolism [24-26]. It is likely many or all of these factors contribute to the cardiovascular health benefits from exercise.

While it is clear, exercise improves hemodynamic profiles and cardiovascular health [,3,6,27-29], very little is known of the significance of interactions between exercise and drug therapy $[30,31]$. Based on very limited amounts of data available, it is believed that chronic exercise may affect drug absorption by increase in collateral blood flow and changes in gastrointestinal transit times. It may also affect volume of distribution of drugs by the increase in lean body mass (and decreases fatty tissue), plasma protein concentrations and plasma volume that occur with physical conditioning. Changes in hepatic clearance and renal excretion of drugs may also occur as a result of increased hepatic enzyme activities, and/or changes in protein binding. However, these effects are highly variable depending on the drug, as well as physical condition of the patients, as the impact from acute exercise may be different from chronic exercise $[32,33]$. It has been shown that exercise increased plasma concentrations of propranolol and atenolol, but not carvedilol or verapamil. On the other hand, increasing physical activity in patients taking warfarin has been shown to decrease the international normalised ratio (INR) [30]. In experimental animal models, exercise has been shown to mitigate anthracycline-induced chronic cardiotoxicity in rats [34]. Most recently, we have shown that a brief period of exercise increased absorption, as well as clearance (CL) and volume of distribution (Vd) of diltiazem (DTZ) after subcutaneous (sc) injection in rats [35]. In addition, exercise can also enhance the cardiovascular protective effect of DTZ [36]. These effects are likely to be individual and therapy specific, and at the current levels of physical activity recommended, not likely to have a significant impact in routine clinical practice. Clinicians should however be aware of the potential for such interactions for drugs with a narrow therapeutic range, and in patients who participate in extreme sporting activities may require dosage adjustment [30,31]. More studies are urgently needed in this area to better understand the complex interactions of therapeutic lifestyle interventions and conventional medical therapy.

*Corresponding author: Yeung PK, Professor of Pharmacy and Medicine 1Department of Medicine, College of Pharmacy, Dalhousie University, Halifax, Canada, Tel: 902-4943845; Fax: 902-4941396; E-mail: Pollen.Yeung@Dal.Ca

Received October 24, 2013; Accepted October 25, 2013; Published October 28,2013

Citation: Yeung PK, Tinkel J (2013) Complementary Effect of Exercise in Cardiovascular Medicine. Cardiol Pharmacol 2: e119. doi:10.4172/2329-6607.1000e119

Copyright: (c) 2013 Yeung PK. This is an open-access article distributed under the terms of the Creative Commons Attribution License, which permits unrestricted use, distribution, and reproduction in any medium, provided the original author and source are credited. 
Citation: Yeung PK, Tinkel J (2013) Complementary Effect of Exercise in Cardiovascular Medicine. Cardiol Pharmacol 2: e119. doi:10.4172/2329$6607.1000 \mathrm{e} 119$

In summary, lack of regular physical activity is increasingly recognized as a major modifiable contributor to the development of CVD, and it is a significant global health problem. Regular physical activity is rapidly becoming an integral part of recommended therapeutic lifestyle interventions to complement traditional therapy for prevention, treatment and recovery from CVD. A more in-depth understanding of the mechanisms involved in the health benefits of exercise, and the interaction with conventional medicines will further advance prevention and management of CVD, resulting in improved outcomes at lower cost, affecting millions worldwide.

\section{References}

1. Roger VL, Go AS, Lloyd-Jones DM, Adams RJ, Berry JD, et al. (2011) Heart disease and stroke statistics update: A report from the American Heart Association. Circulation 123: e18-e209.

2. Go AS, Mozaffarian D, Roger VL, Benjamin EJ, Berry JD, et al. (2013) Heart disease and stroke statistics update: A report from the American Heart Association. Circulation 127: e6-e245.

3. Vogel T, Brechat PH, Lepretre PM, Kaltenbach G, Berthel M, et al. (2009) Health benefits of physical activity in older patients: A review. Int J Clin Pract 63: $303-320$

4. Antic S, Lazarevic G, Velojic M, Dimic D, Stefanovic V (2009) Exercise as a therapeutic option in cardiometabolic risk reduction. Med Pregl 3: 59-65.

5. Prasad DS, Das BC (2009) Physical inactivity: A cardiovascular risk factor Indian J Med Sci 63: 33-42.

6. Blair SN, Morris JN (2009) Healthy hearts and the universal benefits of being physically active: Physical activity and health. Ann Epidemiol 19: 253-256.

7. Scott JM, Koelwyn GJ, Hornsby WE, Khouri M, Peppercorn J, et al. (2013) Exercise therapy as treatment for cardiovascular and oncologic disease after a diagnosis of early-stage cancer. Semin Oncol 40: 218-228.

8. Briet M, Schiffrin EL (2013) Treatment of arterial remodeling in essential hypertension. Curr Hypertens Rep 15: 3-9.

9. Brook RD, Appel LJ, Rubenfire M, Ogedegbe G, Bisognano JD, et al (2013) Beyond medications and diet: alternative approaches to lowering blood pressure: A scientific statement from the American Heart Association. Hypertension 61: 1360-1383.

10. Hunter DJ, Reddy KS (2013) Non communicable diseases. N Engl J Med 369: 1336-1343.

11. Jimenez SK, Jassal DS, Kardami E, Cattini PA (2011) A single bout of exercise promotes sustained left ventricular function improvement after isoproterenolinduced injury in mice. J Physiol Sci 61: 331-336.

12. Shen YJ, Pan SS, Zhuang T, Wang FJ (2011) Exercise preconditioning initiates late cardioprotection against isoproterenol-induced myocardial injury in rats independent of protein kinase C. J Physiol Sci 61:13-21.

13. Yeung PKF, Seto D (2011) Exercise pre-conditioning attenuates cardiovascular toxicities and reduces mortality induced by isoproterenol in a freely moving rat model in vivo. 14: $97 \mathrm{~s}-98 \mathrm{~s}$

14. Crimi E, Ignarro LJ, Cacciatore F, Napoli C (2009) Mechanisms by which exercise training benefits patients with heart failure. Nat Rev Cardiol 6: 292300

15. Blair SN, Kampert JB, Kohl HW 3rd, Barlow CE, Macera CA, et al. (1996) Influences of cardiorespiratory fitness and other precursors on cardiovascular disease and all-cause mortality in men and women. JAMA 276: 205-10.
16. Myers J, Prakash M, Froelicher V, Do D, Partington S, et al. (2002) Exercise capacity and mortality among men referred for exercise testing. $\mathrm{N}$ Engl $\mathrm{J}$ Med 346: 793-801.

17. Gulati M, Pandey DK, Arnsdorf MF, Lauderdale DS, Thisted RA, et al. (2003) Exercise capacity and the risk of death in women: The St James Women Take Heart Project. Circulation 108:1554-1559.

18. Rankin AJ, Rankin AC, Maclntyre P, Hillis WS (2012) Walk or run? Is highintensity exercise more effective than moderate-intensity exercise at reducing cardiovascular risk? Scott Med J 57: 99-102.

19. Hackney AC (2006) Exercise as a stressor to the human neuroendocrine system. Medicina (Kaunas) 42: 788-797.

20. Pedersen BK (2012) Muscular interleukin-6 and its role as an energy sensor Med Sci Sports Exerc 44: 392-396.

21. Pedersen BK (2011) Exercise-induced myokines and their role in chronic diseases. Brain Behav Immun 25: 811-816.

22. Brandt C, Pedersen BK (2010) The role of exercise-induced myokines in muscle homeostasis and the defense against chronic diseases. J Biomed Biotechnol 2010: 520258

23. Yellon DM, Hausenloy DJ (2007) Myocardial reperfusion injury. N Engl J Med 357: 1121-1135.

24. Di Francescomarino S, Sciartilli A, Di Valerio V, Di Baldassarre A, Gallina S (2009) The effect of physical exercise on endothelial function. Sports Med 39:797-812.

25. Kavazis AN (2009) Exercise preconditioning of the myocardium. Sports Med 39: $923-935$

26. Gorman MW, Rooke GA, Savage MV, Jayasekara MP, Jacobson KA, et al (2010) Adenine nucleotide control of coronary blood flow during exercise. Am J Physiol Heart Circ Physiol 299: H1981-H1989.

27. O'Connor, Christopher M, Whellan, David J, Lee, et al. (2009) Efficacy and safety of exercise training in patients with chronic heart failure: HF-ACTION randomized controlled trial. JAMA 301: 1439-1450.

28. Yeung PK, Dauphinee J, Gouzoules T, Simonson K (2010) Exercise improves hemodynamic profiles and increases RBC concentrations of ATP in a rodent model. Clin Pharmacol Ther S42: 2-10.

29. O'Hagan C, De Vito G, Boreham CA (2013) Exercise prescription in the treatment of type 2 diabetes mellitus: Current practices, existing guidelines and future directions. Sports Med 43: 39-49.

30. Lenz TL, Lenz NJ, Faulkner MA (2004) Potential interactions between exercise and drug therapy. Sports Med 34: 293-306.

31. Lenz TL (2011) The effects of high physical activity on pharmacokinetic drug interactions. Expert Opin Drug Metab Toxicol 7: 257-266.

32. Khazaeinia T, Ramsey AA, Tam YK (2000) The effects of exercise on the pharmacokinetics of drugs. J Pharm Pharm Sci 3: 292-302.

33. Persky AM, Eddington ND, Derendorf H (2003) A review of the effects of chronic exercise and physical fitness level on resting pharmacokinetics. Int $J$ Clin Pharmacol Ther 41: 504-516.

34. Hayward R, Lien CY, Jensen BT, Hydock DS, Schneider CM (2012) Exercise training mitigates anthracycline-induced chronic cardiotoxicity in a juvenile rat model. Pediatr Blood Cancer 59: 149-154.

35. Yeung P, Marcoux T (2013) Effect of acute exercise on pharmacokinetics of diltiazem in a freely moving rat model. JPPS 16: $115 \mathrm{~S}$

36. Purcell C, Seeto D, Yeung P (2013) Cardiovascular protective effect of diltiazem in a rat model of acute myocardial infarction with and without exercise. Canadian Journal of Cardiology 29: S291. 